\title{
Risk Early-Warning Method for Natural Disasters Based on Integration of Entropy and DEA Model*
}

\author{
Fengshan Wang, Yan Cao, Meng Liu \\ Engineering Institute of Engineering Corps, PLA University of Science \& Technology, Nanjing, China \\ E-mail:wfs919@tom.com \\ Received September 1, 2010; revised October 31, 2010; accepted November 5, 2010
}

\begin{abstract}
Risk early-warning of natural disasters is a very intricate non-deterministic prediction, and it was difficult to resolve the conflicts and incompatibility of the risk structure. Risk early-warning factors of natural disasters were differentiated into essential attributes and external characters, and its workflow mode was established on risk early-warning structure with integrated Entropy and DEA model, whose steps were put forward. On the basis of standard risk early-warning DEA model of natural disasters, weight coefficient of risk early-warning factors was determined with Information Entropy method, which improved standard risk early-warning DEA model with non-Archimedean infinitesimal, and established risk early-warning preference DEA model based on integrated entropy weight and DEA Model. Finally, model was applied into landslide risk early-warning case in earthquake-damaged emergency process on slope engineering, which exemplified the outcome could reflect more risk information than the method of standard DEA model, and reflected the rationality, feasibility, and impersonality, revealing its better ability on comprehensive safety and structure risk.
\end{abstract}

Keywords: Entropy, Data Envelopment Analysis, Comprehensive Integration, Essential Attribute, Risk Early-Warning, Natural Disaster

\section{Introduction}

Timely and exact early-warning of natural disasters, can effectively reduce loss of life and property, which is an important basis for emergency management and disaster relief decision-making [1].

Risk early-warning is an extremely intricate and dynamic process, its early-warning object is the risk event that was not certain and evident [2]. The relation among the factors that influenced risk was intricacy and complex [3], which often behaved fuzzy, certain, potential, random, conflict, incompatible and other polymorphism [4].

Data Envelopment Analysis (DEA) was brought forward by A. Charnes, W. Cooper, and other scholars of U.S. operations research, which evaluated the relative effectiveness or probability of decision-making unit with changing weight, as an important method for showing relative efficiency evaluation [5]. DEA was strong in its objectivity, and its conclusions from subjective human

*This work is supported by the Chinese NSF grants 70971137. personality, which presents a positive role on risk evaluation [6,7], best selection and sort, effectiveness of forecasting combination, decision-making unit, and other aspects. But, DEA evaluation is entirely dependent on objective data, and can not reflect the preference of the risk early-warning factors in the special risk environment.

Model and method of risk early-warning must adapt to the requirement of natural disasters, as the characteristics of natural disasters are polymorphism, contradictory and incompatible. The comprehensive integration of DEA theory and Information Entropy theory [8], was applied into relational features, structure, function, organization and regulatory mechanisms of complex early-warning issues. It is useful for eliminating the subjective weight when determining the indicator weight, and solving the pivotal contradiction and incompatibility among indicators.

This method of integrated DEA and Entropy was different from other comprehensive evaluation methods for its unified mathematical model. It extracted information entropy from risk early-earning samples, determined the 
entropy weight preference of risk early-warning factors, further carried on the evaluation about the relative risk degree of risk early-warning sample, and finally realized the impersonal, reasonable, accurate, scientific earlywarning decision about the risk natural disaster conditions.

\section{Risk Early-Warning Workflow Mode about Natural Disasters}

\subsection{Early-Warning Characters of Risk Events}

Set $\Psi$ as the abstract sign of earthquake, floods and other natural disasters, and $\Omega$ denoted the potential risk. And, $C_{i}$ denoted the general risk factor of potential risk $\Omega$, whose factor set was denoted as $C=$ $\left\{C_{i} \mid i=1,2, \cdots, m\right\}$.

The movement and evolution of risk $\Omega$ is consistent with the general laws of material movement and social development, which is determined by internal factors, objectively existed in the essential attributes of risk events, such as rock integrity coefficient in the landslide risk of rock slope engineering.

Risk $\Omega$ is random, disordered, which happened as the essential attributes normally activated by a lot of unexpected external factors, such as daily maximum rainfall in the landslide risk of rock slope engineering.

Therefore, the early-warning factors of risk $\Omega$ could be differentiated into essential attributes and external characters. Set $X_{i}$ as the signal risk early-warning external character, $i=1,2, \cdots, r$, and $Y_{i}$ as its signal essential attributes, $i=r+1, \cdots, m$. Then, the early-warning factors of risk $\Omega$, formalized as:

$$
\begin{cases}X=\left[X_{1}, X_{2}, \cdots, X_{i}, \cdots, X_{r}\right]^{T} & 1 \leq i \leq r \\ Y=\left[Y_{r+1}, Y_{r+2}, \cdots, Y_{i}, \cdots, Y_{m}\right]^{T} & r<i \leq m \\ C=X \cup Y & \end{cases}
$$

where early-warning characteristic system was formally denoted for risk $\Omega$. Here, $X$ denoted the set about external characters, and $Y$ denoted the set about essential attributes.

\subsection{Basic Mathematical Expression about Risk Early-Warning Events}

In accordance with the $X$ and $Y$ level classification of risk early-warning factors, based on the low risk expectations of psychological characteristics, the measuring requirement was designed, which provided rules for risk earlywarning samples.

Essential attribute measuring requirement: As $y_{i j}$ denoting the value of risk early-warning sample $E_{j}$ on the essential attribute $C_{i}$ of $Y, y_{i j}$ satisfied the max type, namely the greater measurement and the lower risk.

External character measuring requirement: As $x_{i j}$ denoting the value of risk early-warning sample $E_{j}$ on the external character $C_{i}$ of $X, x_{i j}$ satisfied the min type, namely the lower measurement and the lower risk.

Based on measuring requirement for risk early-warning sample, risk early-warning was essentially to distill risk sample, determine the risk early-warning impersonal data, and further determine the measuring value or the relative risk degree of risk early-warning sample, and finally confirm the important risk early-warning positions.

Accordingly, risk early-warning was denoted formally:

$$
\text { opt }::=\langle C, E, F\rangle
$$

Here, $E$ denoted risk early-warning sample set, including $E_{1}, E_{2}, \cdots, E_{j}, \cdots, E_{n}$. And, $F$ formally denoted the risk early-warning mathematical methods, including parametric, non-parametric methods, and intelligent reasoning method.

In view of the $\min \& \max$ changing characteristics and measuring requirements in risk early-warning factors, risk early-warning function was designed formally, as the following expression in (3).

$$
F_{j}=o p x\left\{\frac{\left[y_{r+1, j}, y_{r+2, j}, \cdots, y_{m, j}\right]_{\max }}{\left[x_{1 j}, x_{2 j}, \cdots, x_{r j}\right]_{\min }}\right\}
$$

where the inherent and external mechanism was indicated through the formal mathematical logic, revealing inherent stability of the risk early-warning sample. Here, $F_{j}$ denoted the risk parameter of the risk early-warning sample, $x_{i j}(1 \leq i \leq r)$ denoted the measurement of sample $E_{j}$ on the external character $X_{i}$, and $y_{i j}$ $(r+1 \leq i \leq m)$ denoted the risk estimation of sample $E_{j}$ on the essential attribute $Y_{i}$.

\subsection{Risk Early-Warning Workflow Model}

According to the risk management requirements of natural disaster $\Psi$, with the extraction the restraint requirement of risk early-warning, and the identification of potential risk event and its related factors, the essential attribute set $Y$ and external character set $X$ was established for the risk early-warning of natural disasters.

Design risk early-warning workflow mode for natural disasters on the integrated basis of Entropy and DEA model, as shown in Figure 1.

Integration of Entropy and DEA model was carried into the natural risk early-warning operations, which mainly contained four stages.

1) Erect the risk early-warning indicator set $C$ of natu- 
ral disaster $\Psi$, and differentiate essential attributes and external characters.

2) Extract the risk early-warning samples for natural disasters, and determine the information entropy preference of essential attribute $Y$ and external character $X$ for risk early-warning.

3) Establish the relative risk early-warning value preference DEA model of natural disaster $\Psi$, and calculate the relative safe degree of the risk early-warning sample.

4) In accordance with Relative Risk Sentencing Guideline, sentence the relative risk degree of risk early- warning samples, and submit the analysis for the risk natural events.

\section{Risk Early-Warning DEA Model for Natural Disasters}

\subsection{Risk Early-Warning Data Structure}

According to the fundamental principle of DEA [9], the relative risk decision-making data structure was erected for risk early-warning samples, as shown in Figure 2.

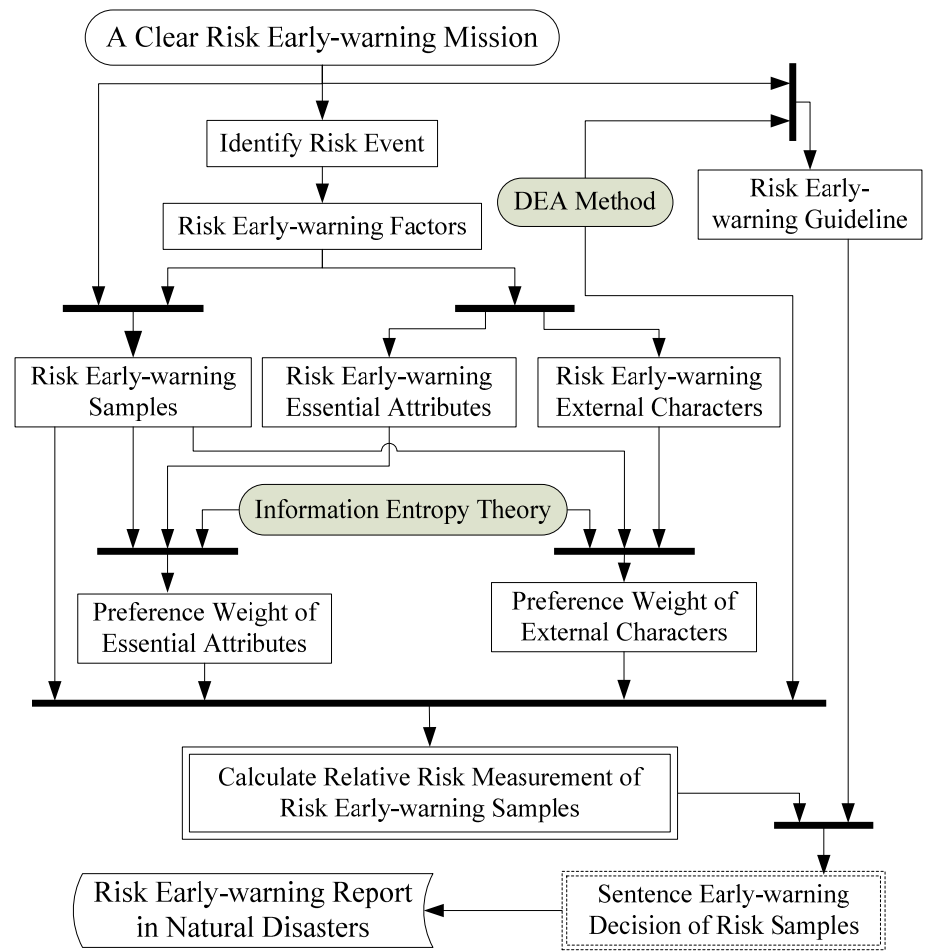

Figure 1. Risk early-warning workflow mode of entropy-based DEA model.

\begin{tabular}{|c|c|c|c|c|c|c|c|c|c|}
\hline & & $E_{1}$ & $E_{2}$ & $\ldots$ & $E_{j}$ & $\ldots$ & $E_{n}$ & & \\
\hline$C_{1}$ & $\rightarrow$ & $x_{1,1}$ & $x_{1,2}$ & $\ldots$ & $x_{1, j}$ & $\ldots$ & $x_{1, n}$ & & \\
\hline$C_{2}$ & $\rightarrow$ & $x_{2,1}$ & $x_{2,2}$ & $\ldots$ & $x_{2, j}$ & $\ldots$ & $x_{2, n}$ & & \\
\hline$\vdots$ & $\vdots$ & $\vdots$ & $\vdots$ & $\vdots$ & $\vdots$ & $\vdots$ & $\vdots$ & & \\
\hline \multirow[t]{5}{*}{$C_{r}$} & $\rightarrow$ & $x_{r, 1}$ & $x_{r, 2}$ & $\ldots$ & $x_{r, j}$ & $\ldots$ & $x_{r, n}$ & & \\
\hline & & $y_{r+1,1}$ & $y_{r+1,2}$ & $\ldots$ & $y_{r+1, j}$ & $\ldots$ & $y_{r+1, n}$ & $\rightarrow$ & $C_{r+1}$ \\
\hline & & $y_{r+2,1}$ & $y_{r+2,2}$ & $\ldots$ & $y_{r+2, j}$ & $\ldots$ & $y_{r+2, n}$ & $\rightarrow$ & $C_{r+2}$ \\
\hline & & $\vdots$ & $\vdots$ & $\ldots$ & $\vdots$ & $\ldots$ & $\vdots$ & $\vdots$ & $\vdots$ \\
\hline & & $y_{m, 1}$ & $y_{m, 2}$ & $\ldots$ & $y_{m, j}$ & $\ldots$ & $y_{m, n}$ & $\rightarrow$ & $C_{m}$ \\
\hline
\end{tabular}

Figure 2. Relative risk decision-making unit structure of risk early-warning samples. 
In Figure 2, the risk early-warning sample $E_{j}$ was converted into decision-making unit $\left(D M U_{j}\right)$ in relative risk decision-making system, and each $D M U_{j}$ had the measurement about $r$ external characters and $m-r$ essential attributes.

With the relative decision-making unit structure of risk early-warning sample, suppose that $\tilde{X}_{j}$ denoted the measurement of risk early-warning sample $E_{j}$ on external character, and $\tilde{Y}_{j}$ denoted its measurement on essential attributes. Then, decision-making unit was denoted formally for the risk early-warning sample as in (4).

$$
\left\{\begin{array}{l}
\tilde{X}_{j}=\left[x_{1, j}, x_{2, j}, \cdots, x_{r, j}\right]^{T} \\
\tilde{Y}_{j}=\left[y_{r+1, j}, y_{r+2, j}, \cdots, y_{m, j}\right]^{T} \\
D M U_{j}=\left\{\left(\tilde{X}_{j}, \tilde{Y}_{j}\right) \mid(j=1,2, \cdots, n)\right\}
\end{array}\right.
$$

where with decision-making unit model of DEA, decision-making data structure was established for risk early-warning sample of natural disaster. Among them, $\tilde{X}_{j}$ signed the characterization about the external risk input vector of decision-making unit, and $\tilde{Y}_{j}$ signed the characterization about the essential safe output vector of decision-making unit.

\subsection{Basic Risk Early-Warning DEA Model}

Formula (3) formally denoted the relative risk analysis about risk early-warning samples, which was similar to DEA efficiency evaluation expression.

Set the risk early-warning sample $E_{1}, E_{2}, \cdots, E_{j}, \cdots$, $E_{n}$ of natural disasters as DEA decision-making unit, analyzing the relative risk of decision-making unit $E_{k}$.

According to DEA model, basic mathematical DEA model was established for natural risk early-warning sample, such as the following formula.

$$
\begin{aligned}
& \max \quad \mu^{T}\left(\tilde{Y}_{k}\right)=V_{p} \\
& \left\{\begin{array}{l}
v^{T} \tilde{X}_{j}-\mu^{T} \tilde{Y}_{j} \geq 0, \\
v^{T} \tilde{X}_{k}=1 \\
v \geq 0, \mu \geq 0, j=1,2, \cdots, n
\end{array}\right.
\end{aligned}
$$

In Formula (5), $v$ denoted the weight vector of risk early-warning external character measurement $\tilde{X}_{j}$, and $\mu$ denoted the weight vector of risk early-warning essential attribute measurement $\tilde{Y}_{j} \cdot V_{p}$ signed the best efficiency evaluation of risk early-warning decisionmaking unit $E_{k}$ for natural disasters, namely the overall safety degree of decision-making unit $E_{k}$ relative to other decision-making units, and there $V_{p} \leq 1$.

\subsection{Risk Early-Warning DEA Model with Non-Archimedean Infinitesimal}

Model (5), was known as standard DEA model, namely $C^{2} R$ model. Other related application showed [10,11], there was often multi-effectiveness phenomenon, so it was not easy to directly determine the effectiveness of DEA. Charnes introduced the concept of non-Archimedean infinitesimal in his study on the degradation phenomenon of linear programming, successfully solved the difficulty in the calculation and technology of $C^{2} R$ model.

Using the dual form of $C^{2} R$ model in DEA method, non-Archimedean infinitesimal relative safe evaluation model was established for risk early-warning samples, such as model (6).

$$
\begin{gathered}
\min V_{p}=\theta-\varepsilon\left(\sum_{i=1}^{r} \alpha_{i}^{-}+\sum_{i=r+1}^{m} \alpha_{i}^{+}\right) \\
\left(D_{\varepsilon}^{I}\right)\left\{\begin{array}{l}
\sum_{j=1}^{n} x_{i j} \lambda_{j}+\alpha_{i}^{-}=\theta x_{i k} \quad i=1, \cdots, r \\
\sum_{j=1}^{n} y_{i j} \lambda_{j}-\alpha_{i}^{+}=y_{i k} \quad i=r+1, \cdots, m \\
\lambda_{j} \geq 0, j=1, \cdots, n \\
\theta, \alpha_{i}^{-}, \alpha_{i}^{+} \geq 0
\end{array}\right.
\end{gathered}
$$

where $V_{p}$ denoted the risk measurement of risk sample $E_{k}$, namely risk early-warning decision-making unit $D M U_{k}$, which was consistent with the $V_{p}$ expression in model (5). Here, $\alpha_{i}^{-}$denoted the slack variable about the external character, $\alpha_{i}^{+}$denoted the slack variable about the essential attribute, and $\varepsilon$ signed the non- Archimedean infinitesimal constant variable, which was less than any positive number, but large than 0 , usually taken on $\varepsilon=10^{-5}$.

\subsection{Relative Risk Sentencing Guideline}

Suppose that the optimal solution of model (6) was $\theta^{0}$, $\lambda^{0}, \alpha_{i}^{0-}, \alpha_{i}^{0+}$, then the relative risk sentencing guideline was established for the early-warning sample $E_{k}$ according to DEA model [6].

Guideline 1: If $\theta^{0}=1$, then the risk early-warning decision-making unit $D M U_{k}$ was evaluated as weak DEA efficiency, and it sentenced the risk early-warning sample $E_{k}$ about natural disasters as relative weak efficiency, namely the weak efficiency in relative safety.

Guideline 2: If $\theta^{0}=1$ and $\sum_{i=1}^{r} \alpha_{i}^{0-}+\sum_{i=r+1}^{m} \alpha_{i}^{0+}=0$, then the risk early-warning decision-making unit $D M U_{k}$ was evaluated as DEA efficiency, and it sentenced the risk early-warning sample $E_{k}$ as relative efficiency, 
namely the efficiency in relative safety for natural disasters.

\section{Improved DEA Model for Risk Early-Warning Sample}

Model (6), calculated relative safe degree of the objective risk early-warning sample data relative safety, which played a positive role in the decision of risk warning measurement; but it hadn't made the best of objective data, and could not reflect preference information of the external character and essential attribute.

\subsection{Standardization of Risk Early-Warning Characteristics}

In accordance with the data expression of decisionmaking unit for risk early-warning sample, as the Formula (4), the initial risk early-warning matrix $\widetilde{R}$ was established for natural disasters in (7).

$$
\tilde{R}=\left[\begin{array}{c|cccccc}
E_{1} & x_{11} & \cdots & x_{r 1} & y_{r+1,1} & \cdots & y_{m, 1} \\
E_{2} & x_{12} & \cdots & x_{r 2} & y_{r+1,2} & \cdots & y_{m, 2} \\
\vdots & \vdots & \vdots & \vdots & \vdots & \ddots & \vdots \\
E_{n} & x_{1 n} & \cdots & x_{r n} & y_{r+1, n} & \cdots & y_{m, n}
\end{array}\right]
$$

With terminal minus, the initial risk early-warning sample matrix $\tilde{R}$ of natural disaster was standardized. If the early-warning factor $C_{i}$ showed the external character, namely the positive effect in natural disasters, then:

$$
x_{i j}^{\prime}=\left[x_{i j}-\min _{1 \leq j \leq n}\left(x_{i j}\right)\right] /\left[\max _{1 \leq j \leq n}\left(x_{i j}\right)-\min _{1 \leq j \leq n}\left(x_{i j}\right)\right]
$$

If the early-warning factor $C_{i}$ showed the essential attribute, namely the negative effect in natural disasters, then:

$$
y_{i j}^{\prime}=\left[\max _{1 \leq j \leq n}\left(y_{i j}\right)-y_{i j}\right] /\left[\max _{1 \leq j \leq n}\left(y_{i j}\right)-\min _{1 \leq j \leq n}\left(y_{i j}\right)\right]
$$

Thus, under the natural disasters emergency, the initial risk early-warning sample matrix $\tilde{R}$ turned into the standard matrix $\stackrel{\bar{R}}{R}$ :

$$
\overline{\bar{R}}=\left[\begin{array}{c|cccccc}
E_{1} & x_{11}^{\prime} & \cdots & x_{r 1}^{\prime} & y_{r+1,1}^{\prime} & \cdots & y_{m, 1}^{\prime} \\
E_{2} & x_{12}^{\prime} & \cdots & x_{r 2}^{\prime} & y_{r+1,2}^{\prime} & \cdots & y_{m, 2}^{\prime} \\
\vdots & \vdots & \vdots & \vdots & \vdots & \ddots & \vdots \\
E_{n} & x_{1 n}^{\prime} & \cdots & x_{r n}^{\prime} & y_{r+1, n}^{\prime} & \cdots & y_{m, n}^{\prime}
\end{array}\right]
$$

\subsection{Preference Information Entropy Calculation on Risk Early-Warning Factors}

The weight value of early-warning factor was a con- cernful information in early-warning structure for risk natural disasters, which was easily impacted by human personality. There was complexity and uncertainty, as well as contradiction in the decision-making process, so it was difficult to estimate the specific factor weight.

Entropy was a measure of uncertain due to the unknown part of a message system [12]. With Entropy theory, the weight value could be determined through the inner components and relations in the risk early-warning system. It was absolutely an impersonal weighting method. This method used entropy value to reflect the degree of information disorder, which could effectively reduce subjective bias on indicator weight.

According to the standard matrix $\overline{\bar{R}}$ for risk earlywarning sample, suppose that $f_{i j}$ showed the proportion of risk early-warning event $E_{j}$ on the risk earlywarning factor $C_{i}$, then:

$$
f_{i j}= \begin{cases}x_{i j}^{\prime} / \sum_{j=1}^{n} x_{i j}^{\prime} & i=1,2, \cdots, r \\ y_{i j}^{\prime} / \sum_{j=1}^{n} y_{i j}^{\prime} & i=r+1, \cdots, m\end{cases}
$$

In terms of the information entropy theory [8], the natural disaster conditions and the risk entropy principles [13], the Shannon entropy value of the early-warning factor $C_{i}$ could be got with the following equation, as shown in (12).

$$
e_{i}=H\left(C_{i}\right)=-\frac{1}{\ln (n)} \sum_{j=1}^{n} f_{i j} \ln \left(f_{i j}\right)
$$

Here, $e_{i}$ said the entropy value of the risk earlywarning samples in natural disaster. As the entropy value show greater, it reflected the greater degree of internal disorder in the natural risk system. As $f_{i j}=0, f_{i j}=$ 0.00001 was set.

Thus, for natural disasters, the weight of risk earlywarning $C_{i}$ was calculated, as:

$$
\left\{\begin{array}{l}
\varpi_{i}=\left(1-e_{i}\right) /\left(n-\sum_{i=1}^{r} e_{i}\right) \quad i=1,2, \cdots, r \\
\varpi_{i}=\left(1-e_{i}\right) /\left(n-\sum_{i=r+1}^{m} e_{i}\right) \quad i=r+1, \cdots, m \\
\sum_{i=1}^{r} \varpi_{i}=\sum_{i=r+1}^{m} \varpi_{i}=1
\end{array}\right.
$$

where $\varpi_{i}$ said the weight value of risk early-warning factor $C_{i}$ in natural disaster event.

\subsection{Risk Early-Warning DEA Model with Preference Entropy Weight}

Make the risk early-warning sample $E_{k}$ of natural dis- 
aster as decision-making unit, and improve the non- Archimedean infinitesimal risk early-warning DEA model according to the preference weight of risk early-warning factor for natural disasters. Then, risk early-warning DEA model with preference entropy weight was established on the risk early-warning sample $E_{k}$, such as model (14).

$$
\begin{aligned}
& \min V_{p}=\theta-\varepsilon\left(\sum_{i=1}^{r} \alpha_{i}^{-}+\sum_{i=r+1}^{m} \alpha_{i}^{+}\right) \\
& \left\{\begin{array}{l}
\sum_{j=1}^{n} x_{i j} \lambda_{j}+\alpha_{i}^{-}=\theta \varpi_{i} \cdot x_{k i} \quad i=1, \cdots, r \\
\sum_{j=1}^{n} y_{i j} \lambda_{j}-\alpha_{i}^{+}=\varpi_{i} \cdot y_{k j} \quad i=r+1, \cdots, m \\
\lambda_{j} \geq 0, j=1, \cdots, n \\
\theta, \alpha_{i}^{-}, \alpha_{i}^{+} \geq 0
\end{array}\right.
\end{aligned}
$$

In model (14), the expression and significance of $\theta$, $\lambda, \alpha_{i}^{-}, \alpha_{i}^{+}$and other variables, were consistent with model (6). And, model (14) carried forward entropy analysis in disaster information systems [14].

\subsection{Risk Early-Warning DEA Sentencing Guideline with Preference Entropy Weight}

Suppose that the optimal solution of model (14) was $\theta^{0}$, $\lambda^{0}, \alpha_{i}^{0-}, \alpha_{i}^{0+}$, whose expression and significance was consistent with model (6). Set $V_{p}\left(E_{k}\right)$ as the relative safe measurement of risk early-warning sample $E_{k}$, and establish risk early-warning entropy DEA sentencing guideline.

Guideline 3: According to the formula (15), determine the order of risk early-warning samples. Then, determine the lowest value on the relative safe measurement of risk early-warning samples, and sentence the corresponding sample as the relative most risk sample unit.

$$
\min _{j}\left\{V_{p}\left(E_{j}\right)\right\}
$$

Guideline 4: Set $V_{p}(\tilde{E})$ as the relative safe grade threshold of risk early-warning samples. If the formula (16) was true, the risk early-warning sample $E_{j}$ was sentenced as key risk early-warning unit.

$$
V_{p}\left(E_{j}\right)<V_{p}(\tilde{E}) \quad j=1,2, \cdots, n
$$

\section{Case study on Risk Early-Warning for Slope Landslide}

\subsection{Initial Data for Risk Early-Warning Event of Slope Landslide Case}

For instance, in emergency response on earthquakedamaged rock slope engineering, potential landslide was the risk event. According to the multi-layer indicator system for evaluating the overall safety on rock slope engineering in reference [15-18], the risk early-warning factors were given, as shown in Table 1.

Here, essential attributes included rock structure, rock mass deformation modulus, rock integrity coefficient, cohesion and internal friction angle; and external characters included slope height, slope angle, maximum daily rainfall, monthly total rainfall, seismic level acceleration, maximum terra stress, surface deformation rate, drainage capability, and others.

In the emergency response process on earthquakedamaged rock slope engineering, it supposed that the risk early-warning sample included $E_{1}, E_{2}, E_{3}, E_{4}, E_{5}$

\begin{tabular}{|c|c|c|c|c|c|c|c|c|c|c|c|c|c|}
\hline \multirow[b]{2}{*}{ Sample } & \multicolumn{8}{|c|}{ External factors ( $\min$ Type) } & \multicolumn{5}{|c|}{ Essential attributes ( $\max$ Type) } \\
\hline & $\begin{array}{l}\text { Slope } \\
\text { height }\end{array}$ & $\begin{array}{l}\text { Slope } \\
\text { angle }\end{array}$ & $\begin{array}{l}\text { Daily } \\
\text { maximum } \\
\text { rainfall }\end{array}$ & $\begin{array}{l}\text { Month } \\
\text { cumulative } \\
\text { rainfall }\end{array}$ & $\begin{array}{c}\text { Seismic } \\
\text { horizontal } \\
\text { acceleration }\end{array}$ & $\begin{array}{c}\text { Maximum } \\
\text { terra } \\
\text { stress }\end{array}$ & $\begin{array}{l}\text { Surface } \\
\text { deformation } \\
\text { rate }\end{array}$ & $\begin{array}{l}\text { Drainage } \\
\text { performance }\end{array}$ & $\begin{array}{c}\text { Rock } \\
\text { structure }\end{array}$ & $\begin{array}{l}\text { Rock mass } \\
\text { deformation } \\
\text { modulus }\end{array}$ & $\begin{array}{c}\text { Rock } \\
\text { integrity } \\
\text { coefficient }\end{array}$ & Cohesion & $\begin{array}{l}\text { Internal } \\
\text { friction } \\
\text { angle }\end{array}$ \\
\hline$E_{1}$ & 0.85 & 26 & 56 & 290 & 0.15 & 12.8 & 0.08 & 0.25 & 71 & 2.7 & 0.43 & 0.12 & 24 \\
\hline$E_{2}$ & 1.15 & 39 & 28 & 245 & 0.09 & 14.7 & 0.26 & 0.49 & 54 & 6.9 & 0.39 & 0.18 & 39 \\
\hline$E_{3}$ & 1.06 & 12 & 89 & 212 & 0.13 & 4.1 & 0.17 & 0.35 & 29 & 7.5 & 0.75 & 0.26 & 14 \\
\hline$E_{4}$ & 0.79 & 21 & 63 & 229 & 0.07 & 4.3 & 0.09 & 0.21 & 89 & 20.5 & 0.64 & 0.21 & 27 \\
\hline$E_{5}$ & 0.54 & 51 & 47 & 192 & 0.31 & 11.8 & 0.32 & 0.83 & 86 & 11.4 & 0.20 & 0.29 & 12 \\
\hline$E_{6}$ & 1.21 & 28 & 19 & 264 & 0.24 & 5.7 & 0.13 & 0.52 & 32 & 8.4 & 0.54 & 0.15 & 25 \\
\hline
\end{tabular}
and $E_{6}$, which needed more important focus, and its relevant factors and value, as shown in Table $\mathbf{1 .}$

Table 1. Value of the early-warning factor for slope landslide risk samples in earthquake-damaged emergency response. 


\subsection{DEA Calculation on Risk Early-Warning}

According to model (6), linear programming model was established on the relative safe evaluation of risk earlywarning, such as model (17).

In model (17), the optimal solution was got, as $V_{p}=0.9987$.

Related variables:

$$
\begin{aligned}
& \lambda^{0}=[0,0,0,0.8889,0,0]^{T}, \theta^{0}=1.0, \\
& \alpha^{0-}=[0.148,7.333,0,86.444,0.088,8.978,0,0.063]^{T}, \\
& \alpha^{0+}=[8.111,15.522,0.139,0.067,0]^{T} .
\end{aligned}
$$

Similarly, the relative safe degree DEA evaluation and its variable values could be obtained for the risk sample $E_{2}, E_{3}, E_{4}, E_{5}, E_{6}$, as shown in Table 2.

According to DEA relative risk sentencing guidelines, as Guideline 1 and Guideline 2, the relative safe measurement of $E_{1}$ was the minimum value, so it was sentenced as the maximum risk sample. And, the relative safe evaluation of $E_{2}, E_{3}, E_{4}, E_{5}$ and $E_{6}$ was all the same 1.0, which said the consistent relative safety. So it showed the degradation phenomenon of risk earlywarning samples, and it was difficult to carefully explain the inherent risks.

Table 2. DEA evaluation about risk early-warning case.

\begin{tabular}{cccccc}
\hline Sample & $V_{p}$ & $\lambda^{0}$ & $\theta^{0}$ & $\alpha^{0-}$ & $\alpha^{0+}$ \\
\hline$E_{1}$ & 0.9987 & {$[0,0,0,0.889,0,0]^{T}$} & 1.0 & {$[0.148,7.333,0,86.444,0.088,8.978,0,0.063]^{T}$} & {$[8.111,15.522,0.139,0.067,0]^{T}$} \\
$E_{2}$ & 1.0 & {$[0,1,0,0,0,0]^{T}$} & 1.0 & {$[0,0,0,0,0,0,0,0]^{T}$} & {$[0,0,0,0,0]^{T}$} \\
$E_{3}$ & 1.0 & {$[0,0,1,0,0,0]^{T}$} & 1.0 & {$[0,0,0,0,0,0,0,0]^{T}$} & {$[0,0,0,0,0]^{T}$} \\
$E_{4}$ & 1.0 & {$[0,0,0,1,0,0]^{T}$} & 1.0 & {$[0,0,0,0,0,0,0,0]^{T}$} & {$[0,0,0,0,0]^{T}$} \\
$E_{5}$ & 1.0 & {$[0,0,0,0,1,0]^{T}$} & 1.0 & {$[0,0,0,0,0,0,0,0]^{T}$} & {$[0,0,0,0,0]^{T}$} \\
$E_{6}$ & 1.0 & {$[1,0,0,0,0,1]^{T}$} & 1.0 & {$[0,0,0,0,0,0,0,0]^{T}$} & {$[0,0,0,0,0]^{T}$} \\
\hline
\end{tabular}

$$
\left\{\begin{array}{l}
\min V_{p}=\theta-\varepsilon\left(\sum_{j=1}^{8} \alpha_{j}^{-}+\sum_{j=1}^{5} \alpha_{j}^{+}\right) \\
0.85 \lambda_{1}+1.15 \lambda_{2}+1.06 \lambda_{3}+0.79 \lambda_{4}+0.54 \lambda_{5}+1.21 \lambda_{6}+\alpha_{1}^{-}=0.85 \theta \\
26 \lambda_{1}+39 \lambda_{2}+12 \lambda_{3}+21 \lambda_{4}+51 \lambda_{5}+28 \lambda_{6}+\alpha_{2}^{-}=26 \theta \\
56 \lambda_{1}+28 \lambda_{2}+89 \lambda_{3}+63 \lambda_{4}+47 \lambda_{5}+19 \lambda_{6}+\alpha_{3}^{-}=56 \theta \\
290 \lambda_{1}+245 \lambda_{2}+212 \lambda_{3}+229 \lambda_{4}+192 \lambda_{5}+264 \lambda_{6}+\alpha_{4}^{-}=290 \theta \\
0.15 \lambda_{1}+0.09 \lambda_{2}+0.13 \lambda_{3}+0.07 \lambda_{4}+0.31 \lambda_{5}+0.24 \lambda_{6}+\alpha_{5}^{-}=0.15 \theta \\
12.8 \lambda_{1}+14.7 \lambda_{2}+4.1 \lambda_{3}+4.3 \lambda_{4}+11.8 \lambda_{5}+5.7 \lambda_{6}+\alpha_{6}^{-}=12.8 \theta \\
0.08 \lambda_{1}+0.26 \lambda_{2}+0.17 \lambda_{3}+0.09 \lambda_{4}+0.32 \lambda_{5}+0.13 \lambda_{6}+\alpha_{7}^{-}=0.08 \theta \\
0.25 \lambda_{1}+0.49 \lambda_{2}+0.35 \lambda_{3}+0.21 \lambda_{4}+0.83 \lambda_{5}+0.52 \lambda_{6}+\alpha_{8}^{-}=0.25 \theta \\
71 \lambda_{1}+54 \lambda_{2}+29 \lambda_{3}+89 \lambda_{4}+86 \lambda_{5}+32 \lambda_{6}-\alpha_{1}^{+}=71 \\
2.7 \lambda_{1}+6.9 \lambda_{2}+7.5 \lambda_{3}+20.5 \lambda_{4}+11.4 \lambda_{5}+8.4 \lambda_{6}-\alpha_{2}^{+}=2.7 \\
0.43 \lambda_{1}+0.39 \lambda_{2}+0.75 \lambda_{3}+0.64 \lambda_{4}+0.20 \lambda_{5}+0.54 \lambda_{6}-\alpha_{3}^{+}=0.43 \\
0.12 \lambda_{1}+0.18 \lambda_{2}+0.26 \lambda_{3}+0.21 \lambda_{4}+0.29 \lambda_{5}+0.15 \lambda_{6}-\alpha_{4}^{+}=0.12 \\
24 \lambda_{1}+39 \lambda_{2}+14 \lambda_{3}+27 \lambda_{4}+12 \lambda_{5}+25 \lambda_{6}-\alpha_{5}^{+}=24 \\
\lambda_{1}, \lambda_{2}, \lambda_{3}, \lambda_{4}, \lambda_{5}, \lambda_{6} \geq 0 \\
\alpha_{1}^{-}, \alpha_{2}^{-}, \alpha_{3}^{-}, \alpha_{4}^{-}, \alpha_{5}^{-}, \alpha_{6}^{-}, \alpha_{7}^{-}, \alpha_{8}^{-}, \alpha_{1}^{+}, \alpha_{2}^{+}, \alpha_{3}^{+}, \alpha_{4}^{+}, \alpha_{5}^{+} \geq 0
\end{array}\right.
$$




\subsection{Risk Early-Warning DEA Model with Entropy Weight}

Risk early-warning samples were prepared in Table $\mathbf{1 .}$ Firstly, standardize the initial risk early-warning data according to Formulas (7), (8), (9) and (10). Then, calculate the entropy value and weight value of the natural risk early-warning indicator according to Formulas (11), (12) and (13), Table 3 showed the entropy value and weight value.

In Table 3, the entropy value reflected the amount of useful information that the early-warning indicators provided for landslide early-warning system in the earthquake-damaged slope engineering. For example, "slope height" showed the maximum entropy value, and its weight value was 0.0803 , which was the minimum weight value in the risk indicators. Information effectiveness of the entropy measurement denoted the changing rule, which has the greater entropy value and the smaller weight value of the risk early-warning factor.

According to model (14), the relative safe entropy DEA evaluation model of risk early-warning sample $E_{1}$ was erected, such as (18).

In model (18), the optimal solution was got, as $V_{p}=2.5362$.

Related variables:

$$
\begin{aligned}
& \lambda^{0}=[0,0,0,0.186,0.048,0]^{T}, \theta^{0}=2.5365, \\
& \alpha^{0-}=[2.537,0,0.253,1.487,20.855,0.026,4.066,0]^{T} \\
& \alpha^{0+}=[0,3.991,0.041,0.029,1.759]^{T} .
\end{aligned}
$$

Similarly, the relative safe degree DEA evaluation and its variable values could be obtained for the risk sample

\begin{tabular}{|c|c|c|c|c|c|c|c|c|c|c|c|c|c|}
\hline Sample & $\begin{array}{l}\text { Slope } \\
\text { height }\end{array}$ & $\begin{array}{l}\text { Slope } \\
\text { angle }\end{array}$ & $\begin{array}{l}\text { Daily } \\
\text { maximum } \\
\text { rainfall }\end{array}$ & $\begin{array}{l}\text { Month } \\
\text { cumulative } \\
\text { rainfall }\end{array}$ & $\begin{array}{c}\text { Seismic } \\
\text { horizontal } \\
\text { acceleration }\end{array}$ & $\begin{array}{c}\text { Maximum } \\
\text { terra } \\
\text { stress }\end{array}$ & $\begin{array}{c}\text { Surface } \\
\text { deformation } \\
\text { rate }\end{array}$ & $\begin{array}{c}\text { Drainage } \\
\text { performance }\end{array}$ & $\begin{array}{c}\text { Rock } \\
\text { structure }\end{array}$ & $\begin{array}{c}\text { Rock mass } \\
\text { deformation } \\
\text { modulus }\end{array}$ & $\begin{array}{c}\text { Rock } \\
\text { integrity } \\
\text { coefficient }\end{array}$ & Cohesion & $\begin{array}{l}\text { Internal } \\
\text { friction } \\
\text { angle }\end{array}$ \\
\hline Entropy & 0.8623 & 0.8277 & 0.8131 & 0.8304 & 0.7564 & 0.7129 & 0.7279 & 0.7540 & 0.7603 & 0.8856 & 0.8322 & 0.8320 & 0.8684 \\
\hline
\end{tabular}
$E_{2}, E_{3}, E_{4}, E_{5}, E_{6}$, as shown in Table 4.

Table 3. Entropy value and weight value of the risk early-warning factor for slope landslide risk case.

$$
\left\{\begin{array}{l}
\min V_{p}=\theta-\varepsilon\left(\sum_{j=1}^{8} \alpha_{j}^{-}+\sum_{j=1}^{5} \alpha_{j}^{+}\right) \\
0.85 \lambda_{1}+1.15 \lambda_{2}+1.06 \lambda_{3}+0.79 \lambda_{4}+0.54 \lambda_{5}+1.21 \lambda_{6}+\alpha_{1}^{-}=0.85 \times 0.0803 \theta \\
26 \lambda_{1}+39 \lambda_{2}+12 \lambda_{3}+21 \lambda_{4}+51 \lambda_{5}+28 \lambda_{6}+\alpha_{2}^{-}=26 \times 0.1004 \theta \\
56 \lambda_{1}+28 \lambda_{2}+89 \lambda_{3}+63 \lambda_{4}+47 \lambda_{5}+19 \lambda_{6}+\alpha_{3}^{-}=56 \times 0.109 \theta \\
290 \lambda_{1}+245 \lambda_{2}+212 \lambda_{3}+229 \lambda_{4}+192 \lambda_{5}+264 \lambda_{6}+\alpha_{4}^{-}=290 \times 0.0989 \theta \\
0.15 \lambda_{1}+0.09 \lambda_{2}+0.13 \lambda_{3}+0.07 \lambda_{4}+0.31 \lambda_{5}+0.24 \lambda_{6}+\alpha_{5}^{-}=0.15 \times 0.142 \theta \\
12.8 \lambda_{1}+14.7 \lambda_{2}+4.1 \lambda_{3}+4.3 \lambda_{4}+11.8 \lambda_{5}+5.7 \lambda_{6}+\alpha_{6}^{-}=12.8 \times 0.1674 \theta \\
0.08 \lambda_{1}+0.26 \lambda_{2}+0.17 \lambda_{3}+0.09 \lambda_{4}+0.32 \lambda_{5}+0.13 \lambda_{6}+\alpha_{7}^{-}=0.08 \times 0.1586 \theta \\
0.25 \lambda_{1}+0.49 \lambda_{2}+0.35 \lambda_{3}+0.21 \lambda_{4}+0.83 \lambda_{5}+0.52 \lambda_{6}+\alpha_{8}^{-}=0.25 \times 0.1434 \theta \\
71 \lambda_{1}+54 \lambda_{2}+29 \lambda_{3}+89 \lambda_{4}+86 \lambda_{5}+32 \lambda_{6}-\alpha_{1}^{+}=71 \times 0.2918 \\
2.7 \lambda_{1}+6.9 \lambda_{2}+7.5 \lambda_{3}+20.5 \lambda_{4}+11.4 \lambda_{5}+8.4 \lambda_{6}-\alpha_{2}^{+}=2.7 \times 0.1392 \\
0.43 \lambda_{1}+0.39 \lambda_{2}+0.75 \lambda_{3}+0.64 \lambda_{4}+0.20 \lambda_{5}+0.54 \lambda_{6}-\alpha_{3}^{+}=0.43 \times 0.2042 \\
0.12 \lambda_{1}+0.18 \lambda_{2}+0.26 \lambda_{3}+0.21 \lambda_{4}+0.29 \lambda_{5}+0.15 \lambda_{6}-\alpha_{4}^{+}=0.12 \times 0.2045 \\
24 \lambda_{1}+39 \lambda_{2}+14 \lambda_{3}+27 \lambda_{4}+12 \lambda_{5}+25 \lambda_{6}-\alpha_{5}^{+}=24 \times 0.1603 \\
\lambda_{1}, \lambda_{2}, \lambda_{3}, \lambda_{4}, \lambda_{5}, \lambda_{6} \geq 0 \\
\alpha_{1}^{-}, \alpha_{2}^{-}, \alpha_{3}^{-}, \alpha_{4}^{-}, \alpha_{5}^{-}, \alpha_{6}^{-}, \alpha_{7}^{-}, \alpha_{8}^{-}, \alpha_{1}^{+}, \alpha_{2}^{+}, \alpha_{3}^{+}, \alpha_{4}^{+}, \alpha_{5}^{+} \geq 0
\end{array}\right.
$$


Table 4. Entropy DEA assessment for risk early-warning case.

\begin{tabular}{ccccccc}
\hline Sample & $V_{p}$ & $\lambda^{0}$ & $\theta^{0}$ & $\alpha^{0-}$ & $\alpha^{0+}$ \\
\hline$E_{1}$ & 2.5362 & {$[0,0,0,0.186,0.048,0]^{T}$} & 2.5365 & {$[2.537,0,0.253,1.487,20.855,0.026,4.066,0]^{T}$} & {$[0,3.991,0.041,0.029,1.759]^{T}$} \\
$E_{2}$ & 2.7581 & {$[0,0.19,0,0.007,0.057,0]^{T}$} & 2.7582 & {$[0,0.337,0,7.785,0,3.29,0.045,0.052]^{T}$} & {$[0,1.136,0.01,0.015,2.028]^{T}$} \\
$E_{3}$ & 2.4959 & {$[0,0,0.169,0.041,0.003,0]^{T}$} & 2.4961 & {$[0,0,0,6.507,6.754,0.021,0.816,0.034,0.056]^{T}$} & {$[0.261,1.083,0,0,1.245]^{T}$} \\
$E_{4}$ & 3.492 & {$[0,0,0,0.2529,0.0402,0]^{T}$} & 3.4922 & {$[0,0,6.156,13.448,0.005,0.952,0.014,0.019]^{T}$} & {$[0,2.79,0.039,0.022,2.984]^{T}$} \\
$E_{5}$ & 3.6336 & {$[0,0,0,0,0.292,0]^{T}$} & 3.6339 & {$[0,3.725,4.902,12.977,0.07,3.735,0.091,0.19]^{T}$} & {$[0,1.74,0.018,0.025,1.58]^{T}$} \\
$E_{6}$ & 2.5951 & {$[0,0.007,0,0,0.035,0.186]^{T}$} & 2.5952 & {$[0,0.03,0,10.187,0.032,0.902,0.016,0.064]^{T}$} & {$[0,0.842,0,0.009,1.335]^{T}$} \\
\hline
\end{tabular}

According to risk early-warning entropy DEA sentencing guideline, namely Guideline 3, the relative safe order of the risk early-warning disaster samples could be obtained as $V_{p}\left(E_{3}\right)<V_{p}\left(E_{1}\right)<V_{p}\left(E_{6}\right)<V_{p}\left(E_{2}\right)$ $<V_{p}\left(E_{4}\right)<V_{p}\left(E_{5}\right)$.

In accordance with Guideline 4, set the relative safe threshold of the risk early-warning samples as $V_{p}(\tilde{E})=3.0$, then sentence the risk sample $E_{3}, E_{1}$, $E_{6}, E_{2}$ as the important risk early-warning units.

Comparing the calculation outcome of landslide risk case of earthquake-damaged emergency response in Table 2 and Table 4, entropy DEA model could explore more information, whose conclusion was more reliable than the standard DEA model, benefiting the sentencing about the relative risk measurement of risk early-warning samples for natural disasters.

\section{Conclusions}

1) Differentiate the risk early-warning factors of natural disasters into essential attributes and external characters. Using the integration of Entropy and DEA model, risk early-warning model was erected. It made the best of information, and had high reliability. This algorithm was easy to realize by computer software, and had good results. It was a new way for risk early-warning of natural disasters.

2) Determinating the weight value of natural risk early warning indicator through entropy value, solved the conflicts and incompatibilities among indicators, and eliminated the effect of random personality.

3) Risk landslide early-warning case in earthquake emergency response testified, that entropy DEA model explored more implicit preference information of essential attributes and external characters in early-warning samples, whose outcome reflected more additional risk information than the standard DEA model, effectively improving the sentencing on relative risk degree of early- warning samples for natural disasters.

4) Entropy DEA model integrated the objectivity of DEA model and the information entropy of early-warning samples, whose essence was the preference DEA model based on entropy weight. And, its result was more realistic and widely useful. But how to assess core factors in risk early-warning system needed further exploration.

\section{References}

[1] M. Jarraud, "Reducing the Risk of Natural Disasters through Early Warnings," Bulletin of the American Meteorological Society, Vol. 86, No. 2, 2005, pp. 155-156.

[2] V. Selman, A. L. Selman and J. Selman, "Earthquake/ Quackery: The Science/Art of Predicting Natural Disasters," Simulation Series, Vol. 15, No. 1, 1985, pp. 113117.

[3] H. Yang and R. F. Adler, "Towards an Early-Warning System for Global Landslides Triggered by Rainfall and Earthquake," International Journal of Remote Sensing, Vol. 28, No. 16, 2007, pp. 3713-3719. doi:10.1080/ 01431160701311242

[4] K. Kubo, "Prediction and Its Reliability," Civil Engineering in Japan, Vol. 26, No. 12, 1987, pp. 1-10.

[5] A. Charnes, W. W. Cooper and E. Rhodes, "Measuring the Efficiency of Decision-Making Units," European Journal of Operational Research, Vol. 2, No. 6, 1978, pp. 429-444. doi:10.1016/0377-2217(78)90138-8

[6] J. K. Sengupta, "Measuring Dynamic Efficiency under Risk Aversion," European Journal of Operational Research, Vol. 74, No. 1, 1994, pp. 61-69. doi:10.1016/ 0377-2217(94)90203-8

[7] Z.-X. Ma and H.-L. Ren, "An Evaluation Method Based on Some Sample Units and Its Applying on FSA," Systems Engineering-Theory \& Practice, Vol. 23, No. 2, 2003, pp. 96-100.

[8] Y. Horibe, "Entropy and Correlation," IEEE Transactions on Systems, Man and Cybernetics, Vol. SMC-15, No. 5, 1985, pp. 641-642. 
[9] J. K. Sengupta, "Efficiency Measurement in Stochastic Input-Output Systems," International Journal of Systems Science, Vol. 13, No. 3, 1982, pp. 273-287. doi:10.1080/ 00207728208926348

[10] Y.-M. Wang and Y. Luo, "DEA Efficiency Assessment Using Ideal and Anti-ideal Decision-Making Units," Applied Mathematics and Computation (New York), Vol. 173, No. 2, 2006, pp. 902-915.

[11] S. Mehrabian, M. R. Alirezaee and G. R. Jahanshahloo, "Complete Efficiency Ranking of Decision-Making Units in Data Envelopment Analysis," Computational Optimization and Applications, Vol. 14, No. 2, 1999, pp. 261266. doi:10.1023/A:1008703501682

[12] L. S. Qu, L. M. Li and J. Lee, "Enhanced Diagnostic Certainty Using Information Entropy Theory," Advanced Engineering Information, Vol. 17, No. 3-4, 2003, pp. 141-150. doi:10.1016/j.aei.2004.08.002

[13] J. J. Buckley, "Entropy Principles in Decision-Making under Risk," Risk Analysis, Vol. 5, No. 4, 1985, pp. 303-313. doi:10.1111/j.1539-6924.1985.tb00186.x

[14] S. Bilgi, C. Ipbuker, D. Ucar and M. Sahin, "Map Entro- py Analysis of Topographic Data Used in Disaster Information Systems," Journal of Earthquake Engineering, Vol. 12, No. S2, 2008, pp. 23-36.

[15] X. L. Tan, W. Y. Xu and G. L. Liang, "Application of Extenics Method to Comprehensive Safety Evaluation of Rock Slope," Chinese Journal of Rock Mechanics and Engineering, Vol. 28, No. 12, 2009, pp. 2503-2509.

[16] Y. P. Yin, F. W. Wang and P. Sun, "Landslide Hazards Triggered by the 2008 Wenchuan Earthquake, Sichuan, China," Landslides, Vol. 6, No. 2, 2009, pp. 139-151. doi:10.1007/s10346-009-0148-5

[17] G. Q. Chen, "Practical Techniques for Risk Analysis of Earthquake-Induced Landslide," Chinese Journal of Rock Mechanics and Engineering, Vol. 27, No. 12, 2008, pp. 2395-2402.

[18] C.-T. Lee, C.-C. Huang, J.-F. Lee, K.-L. Pan, M.-L. Lin and J.-J. Dong, "Statistical Approach to EarthquakeInduced Landslide Susceptibility," Engineering Geology, Vol. 100, No. 1-2, 2008, pp. 43-58. doi:10.1016/j.enggeo. 2008.03.004 